\title{
Corrigendum
}

\section{Corrigendum to "Analysis of the Creeping Phenomenon of Linear Feed System Based on the Rigid-Flexible Coupling Model"}

\author{
Ruijun Liang, Wenlong Hao, Wenfeng Ran, and Wenhua Ye \\ College of Mechanical and Electrical Engineering, Nanjing University of Aeronautics and Astronautics, Nanjing 210016, China \\ Correspondence should be addressed to Ruijun Liang; lruijun@nuaa.edu.cn \\ Received 24 September 2021; Accepted 24 September 2021; Published 11 October 2021 \\ Copyright (C) 2021 Ruijun Liang et al. This is an open access article distributed under the Creative Commons Attribution License, \\ which permits unrestricted use, distribution, and reproduction in any medium, provided the original work is properly cited.
}

In the article titled "Analysis of the Creeping Phenomenon of Linear Feed System Based on the Rigid-Flexible Coupling Model" [1], the correct affiliation for all authors is as shown above.

\section{Conflicts of Interest}

The authors declare that they have no conflicts of interest.

\section{References}

[1] R. Liang, W. Hao, W. Ran, and W. Ye, "Analysis of the creeping phenomenon of linear feed system based on the rigid-flexible coupling model," Shock and Vibration, vol. 2021, Article ID 9928733, 11 pages, 2021. 